\title{
THE EFFECT OF ER,CR.YSGG LASER ON THE SHEAR BOND STRENGTH OF COMPOSITE RESIN BONDED TO PRIMARY ENAMEL "AN IN-VITRO STUDY"
}

\author{
Reem E.Elkady*, Ola Abd El-Geleel ${ }^{* *}$ and Amr Abdelaziz***
}

\begin{abstract}
Aims and Objectives: The success of composite resin depends mainly on the bond strength of the restoration to the tooth structure. The type of adhesive, the substrate and the surface treatment are the most important factors that affect the bond strength of composite resin restorations. Despite the fact that phosphoric acid is the standard in enamel pretreatment with the best shear bond strength shown with composites in primary teeth. The aprismatic outer enamel layer distinctive to primary teeth could compromise the bond strength and result in a defective superficial etching pattern. Lasers have been studied as surface pretreatment agents with limited applications in primary teeth. Primary enamel pre-conditioning using erbium, chromium:yttrium-scandium-gallium-garnet (Er, Cr:YSGG) yielded controversial results as regards to enhancing enamel bond strength of composite resins to primary enamel.
\end{abstract}

Aim: The aim of the study is to evaluate and compare the shear bond strength of composite resin bonded to enamel which is pretreated using conventional phosphoric acid etchant and Er,Cr:YSGG laser pretreatment.

Materials and Methods: Thirty extracted human primary molar teeth were divided into three groups, $(\mathrm{N}=10)$ in each (Groups I, II and III). Group I, prepared surface of enamel was etched using 37\% phosphoric acid (Scotchbond, 3M). Group II, enamel was surface treated by an Er, Cr: YSGG laser system (Waterlase MD, Biolase Technology Inc., San Clemente, CA, USA) and Group III, a combination of etching and laser treatment was performed. The bonding agent (Scotchbond Multipurpose, 3M) was then applied over the test areas and light cured. Composite resin (Filtek ${ }^{\mathrm{TM}}$ Z250 XT Nano-hybrid Universal restorative, 3M Espe) was later applied and light cured. The samples were finally tested for the shear bond strength.

Results: The Mean shear bond strength for Group III was the highest $(23.2 \pm 0.44 \mathrm{MPa})$ Followed by Group I $(17.4 \pm 0.66 \mathrm{MPa})$, these values were significantly higher $(P<0.01)$ than that of Group II $(10.1 \pm 0.71 \mathrm{MPa})$.

\footnotetext{
* Teaching Assistant; Pediatric Dentistry Department, Faculty of Dentistry, Misr International University, Cairo, Egypt. ** Lecturer; Pediatric Dentistry and Dental public health. Faculty of Dentistry, Ain-Shams University, Cairo, Egypt. *** Professor; Pediatric dentistry and Dental Public Health, Faculty of Dentistry, Ain-Shams University, Cairo, Egypt.
} 
Conclusion: ER,Cr.YSGG laser pretreatment of primary enamel can improve the bond strength of composite resin bonded to acid etched primary enamel, however; it cannot replace the acid etching.

KEYWORDS: primary enamel etching; laser etching; shear bong strength; phosphoric acid etching; erbium; chromium:yttrium,scandium, gallium, garnet laser

\section{INTRODUCTION}

The success of composite resin restoration depends mainly on the bond strength of the restoration to the tooth structure ${ }^{(1)}$. A strong bond between composite resin restorations and the tooth structure is very imperative to avoid post-operative failure modes in forms of marginal leakage, wear, postoperative hypersensitivity, restoration fracture and secondary caries ${ }^{(2)}$.

There is a myriad of factors which influence the bond strength between the resinous restorations and the tooth structure. Of which are; the type of adhesive, composite resin, application technique, thickness of the material in use, depth of curing, testing method, moisture control and the nature of substrate, which is considered one of the most important factors affecting the bonding performance of adhesives systems ${ }^{(3,4)}$.

As a substrate, primary enamel has unique characteristics as it is thinner, less mineralized, has a higher organic content, higher solubility and altered surface charge in comparison to permanent enamel (5). The increased permeability and pore volume accounts for the whitish and opaque appearance of primary enamel ${ }^{(6)}$. All of these features might be attributed to the reduced time available for enamel maturation ${ }^{(5)}$.

In addition, the outer surface zone of enamel appears as a structure of prismless tissue, known as the aprismatic layer in morphological analyses. The aprismatic layer is more frequently seen in primary teeth, where the width of the zone is larger than permanent teeth ${ }^{(7)}$. All the aforementioned properties, account for a difference in the etching capacity, bonding mechanism and bonding efficacy of the resinous material to primary enamel. Thus, bonding of restorations especially to primary enamel is considered a challenging procedure and must be well evaluated ${ }^{(8)}$.

In order to enhance the bond strength between the tooth and the resin composite, surface treatment is an essential step ${ }^{(9)}$. Conventional pretreatment of the enamel surface includes the use of various concentrations of phosphoric acid to create micro porosity, which helps in the formation of the micromechanical bond at the enamel restoration interface ${ }^{(10,11)}$. However, acid etching entails various disadvantages which include technique sensitivity and difficulty in obtaining isolation and on top of all, acid demineralization might result in a tooth structure more susceptible to caries because of demineralization of the most superficial layer especially when resin impregnation is defective because of air bubbles or saliva contamination. ${ }^{(10-}$ 15). These disadvantages have resulted in research for alternatives when preparing enamel surfaces to receive adhesives ${ }^{(16)}$. Among these alternatives, is the use Lasers that have been studied as enamel pretreatment agents, but with limited application in primary teeth ${ }^{(17,18)}$.

Laser etching can follow tooth ablation procedures, and it has the advantages of being painless with no vibration or heat production thereby; making it more attractive and comfortable for young children ${ }^{(17,19)}$.

On the microscopic level it was found that Erbium laser when applied to hard dental tissues, it results in thermo-mechanical wear and evaporation of water content. This results in expansion and disposal of organic and inorganic tissues, open dentinal tubules 
and removal of the smear layer, ultimately leading to a surface with an irregular surface texture and altered calcium-phosphorus ratio, resulting in the development of more stable complexes ${ }^{(20,21)}$. This decreases the vulnerability of laser treated enamel to acid attacks and dental caries ${ }^{(22)}$. All these outcomes are particularly beneficial for the adhesion at the enamel interface in primary teeth.

Laser etching of permanent enamel has been extensively investigated and compared to the outcome of acid etching and yet the results came with a wide disparity in terms of comparable ${ }^{(23,24)}$, higher ${ }^{(25)}$ and lower ${ }^{(26)}$ bond strength values, compared with that of acid etching, depending on the laser type, irradiation parameters and experimental designs $^{(21)}$. Studies on primary enamel however, are limited and particular attention need to be given to improve the quality of bonding in the presence of its challenging features.

This study was conducted with aim of finding the best primary enamel pretreatment protocol by comparing the shear bond strength (SBS) of composite resin bonded to primary enamel using conventional acid etching, laser etching or the combination of both techniques.

\section{MATERIALS AND METHODS}

A total of (30) primary second molars were included in this study, the teeth were collected from the discarded teeth that were freshly extracted at the Pediatric Dentistry and Dental Public Health Department, Faculty of Oral and Dental Medicine. (Ain-Shams University and Misr International University).

The sample teeth were selected only if they were caries free at their buccal surfaces and showing no cracks or enamel defects. The teeth were then randomly allocated into 3 groups (10 specimens in each) according to the enamel pretreatment procedure:

Group I: Acid-etch group

Group II: Er,Cr.YSGG laser pretreatment group

Group III: Er,Cr.YSGG laser pretreatment followed by acid-etching of the irradiated enamel group

The extracted teeth were washed by distilled water, cleaned by $\mathrm{NSK}^{\mathrm{TM}}$ ultrasonic scaler to remove hard and soft deposits, finally examined with transillumination to ensure being free of any cracks or caries.

Each tooth was cut at $2 \mathrm{~mm}$ below cementenamel junction and sectioned mesiodistally into two halves under copious air-water coolant using a diamond disc $^{*}$ in a low speed straight hand piece, and stored in distilled water (for a maximum of one month) before preparation for bond strength test ${ }^{(27)}$.

Each sectioned half was totally embedded in chemical cured acrylic resin ${ }^{* *}$ placed in polyvinyl ring such that the dentin side was embedded within the acrylic and the buccal enamel surfaces were exposed for bonding in order to allow for standardized and secured placement during SBS testing ${ }^{(28)}$.

A (320 grit) Sandpaper ${ }^{* * *}$ was used for flattening \& (400 and 600 grit) sand papers were used for smoothening of the enamel surface, using a figure of 8 motion under water coolant in order to obtain a smooth flat surface ready for bonding of composite resin. The specimens were then cleaned with running water and ultrasonic cleaner to ensure absence of any debris on the surface ${ }^{(27)}$.

\footnotetext{
* D \& Z Germany ${ }^{\mathrm{TM}}$

** Acrostone $\mathrm{T}^{\mathrm{TM}}$

*** Premium Latex Back ${ }^{\mathrm{TM}}$
} 
$37 \%$ phosphoric acid etchant gel* was applied to the enamel surfaces of (Group I) specimens and left in place for 15 seconds after which it was rinsed using an air-water syringe for another 15 seconds and air dried for 10 seconds ${ }^{(29)}$.

As for (Group II \& III) specimens, laser etching was done with an Er,Cr:YSGG** laser system operating at a wavelength of $(2780 \mathrm{~nm})$ and having pulse duration of $60 \mu \mathrm{s}$ (H-Mode), with a repetition rate of $50 \mathrm{~Hz}$, in a non-contact mode with a distance of $2 \mathrm{~mm}$ from the enamel surface at an angle $45^{\circ}$. The power output was set at $2 \mathrm{~W}$. Air and water spray from the handpiece was adjusted to a level of $60 \%$ air and $80 \%$ water for to prevent the enamel surfaces from overheating, the average exposure time was set at $10 \mathrm{~s}$. Laser energy was delivered through a fiberoptic system to a sapphire tip terminal that was $800 \mu \mathrm{m}$ in diameter (Tip=MZ 8), using gold hand piece. ${ }^{(30,31)}$ Only (Group III specimens) received an additional acid etching step following laser pretreatment.

A disposable micro brush was used to apply the adhesive ${ }^{* * *}$ on the pre-treated surfaces for 20 $\mathrm{s}$, then gentle air drying for 5 seconds according to the manufacture instructions was done till complete evaporation of the solvent which was assessed by the absence of motion of the adhesive layer on the tooth upon application of air. The adhesive was then light cured for 20 seconds with Elipar ${ }^{\mathrm{TM}}$ light cure ${ }^{* * * *}$ with a light intensity $1200 \mathrm{Mw} / \mathrm{cm}^{2}$ - which was periodically checked using a radiometer ${ }^{(32)}$. Rubber Tygon $^{\mathrm{TM}}{ }^{* * * * *}$ catheters of $2 \mathrm{~mm}$ internal diameter and $2 \mathrm{~mm}$ height were placed on the etched enamel surfaces to act as a mold for the composite. Resin composite $^{* * * * * *}$ was then packed inside the catheters, covered by celluloid strip and then light cured for 20s, afterwards, the catheters were cut by a lancet and disposed and the specimens were stored in normal saline at $37^{\circ} \mathrm{C}$ for 24 hours before testing ${ }^{(27)}$.

The SBS was measured using universal testing machine ${ }^{* * * * * * *}$ with constant cross head speed of 1 $\mathrm{mm} / \mathrm{min}$, using a chisel driving the load onto the specimen at the enamel- composite interface till debonding took place and shear bond strength was recorded in newtons ${ }^{(33)}$.

\section{Statistical analysis}

Numerical data were explored for normality by checking the data distribution and using Kolmogorov-Smirnov and Shapiro-Wilk tests. Data showed non-parametric (non-normal) distribution. Data were represented as mean, standard deviation (SD), median, range and 95\% Confidence interval for the mean $(95 \% \mathrm{CI})$ values. Kruskal-Wallis test was used to compare between the five groups. Dunn's test was used for pair-wise comparisons. The significance level was set at $\mathrm{P} \leq 0.05$. Statistical analysis was performed with IBM ${ }^{\circledR}$ SPSS $^{\circledR}$ Statistics Version 20.

\section{RESULTS}

Pair-wise comparisons between the groups revealed that Group III showed the highest mean shear bond strength followed by group I. while Group II demonstrated the least mean shear bond strength. The combined laser and acid etched enamel displayed a mean SBS of $(23.2 \pm 0.44 \mathrm{MPa})$ which was statistically significantly higher $(P<0.01)$ than that for laser-etched enamel $(10.1 \pm 0.71 \mathrm{MPa}$, (Table 1)

\footnotetext{
* 3M Scotchbond etchant, 3M dental products, St.paul, MN USA

** Waterlase MD, Biolase Technology Inc., San Clemente, CA, USA

*** Adper Single Bond ,3m Espe, Saint Paul, Minnesota, USA

**** Elipar S10 free light, 3m Espe, USA

***** TYGON® ND 100-65 Medical Tubing

$* * * * * *$ Filtek $^{\mathrm{TM}} \mathrm{Z} 250 \mathrm{XT}$ Nano-hybrid Universal restorative, 3M Espe

******* LLOYD LR 5k, Lloyd Instruments Ltd., Hampshire, UK
} 
TABLE (1) Descriptive statistics and result of Kruskal-Wallis test for comparing the shear bond strength among the test groups

\begin{tabular}{|c|c|c|c|c|c|c|c|c|}
\hline \multirow{2}{*}{ Group } & \multirow{2}{*}{ Mean } & \multirow{2}{*}{ SD } & \multirow{2}{*}{ Median } & \multirow{2}{*}{ Range } & \multicolumn{2}{|c|}{$95 \%$ CI } & \multirow{2}{*}{$P$-value } & \multirow{2}{*}{$\begin{array}{c}\text { Effect size } \\
\text { (Eta squared) }\end{array}$} \\
\hline & & & & & Lower bound & Upper bound & & \\
\hline Group I & $17.4 \mathrm{AB}$ & 4.6 & 17.7 & $8.9-24$ & 14.1 & 20.7 & & \\
\hline Group II & $10.1^{\text {в }}$ & 4.9 & 9.1 & $4.5-17.5$ & 6.6 & 13.6 & $0.001 *$ & 0.319 \\
\hline Group III & $23.2^{\mathrm{A}}$ & 8.5 & 22.5 & $11.4-35.8$ & 17.1 & 29.3 & & \\
\hline
\end{tabular}

*: Significant at $P \leq 0.05$, Different superscripts are statistically significantly different

\section{DISCUSSION}

Treating pediatric patients with laser can be appealing for pediatric dentists, as it is less fearful to the child and better accepted by the parents. Furthermore, it had been proposed that hard dental structures can be ablated using laser beam without the need of local anesthesia, which improves the patient's comfort and cooperation ${ }^{(34)}$.

In the recent years, Erbium family lasers have become popular for hard and soft tissue applications in dentistry. Mainly due to their ability to ablate enamel and dentin since their beams are properly absorbed by water and hydroxyapatite crystals ${ }^{(35)}$. It is reported that the calcium-to-phosphate ratio of hard tissues irradiated by erbium lasers is altered resulting in the formation of compounds that are less soluble by acid attack, which renders these surfaces more resistant to future decay ${ }^{(36)}$. This property in particular could be advantageous in enamel pretreatment procedure as opposed to acid etching. As the later technique removes the superficial protective enamel layer, making the teeth more vulnerable to long-term acid attacks ${ }^{(37)}$.

In the current study, the lowest shear bond strength values of resin composite bonded to primary enamel were obtained in the laser etch group. It could be argued that this diminished mean SBS might be predisposed by the development of subsurface microcracks and fissuring caused by the energy of the laser beam which might adversely affect proper resin penetration at the toothrestoration interface of the laser etched surfaces as claimed by Martínez - Insua et al. ${ }^{(37)}$. And since these values were statistically significantly lower than those of combined laser/acid etch group, and statistically comparable, yet lower than the values of the acid etch group, these findings imply that an additional step of acid etching following laser conditioning might aid in rendering the enamel surface more subject to better resin penetration and hence higher SBS.

The literature is abundant regarding comparing the effects of acid etching versus laser etching of permanent enamel, however, there seems no consensus in terms of the efficacy of the laser etching. Some studies in permanent enamel have concurrent results as this study. Dilip et al. ${ }^{(38)}$, concluded that laser etching and acid etching yielded comparable shear bond strength at power output of $1.5 \mathrm{~W} / 20 \mathrm{~s}$, also Basaran et al. ${ }^{(39)}$, reported that the mean SBS obtained with an Er, Cr: YSGG laser (operated at 1W or $2 \mathrm{~W}$ for $15 \mathrm{~s}$ ), though was lower compared to that of acid etching, the authors claimed that the mean SBS of all the groups were clinically acceptable, on the other hand they did not recommend lower power outputs, as SBS diminished dramatically below (1watt) according to their report.

Another interesting study by Shafiei et al. ${ }^{(21)}$, concluded that the usage of universal adhesives was the tipping point in enhancing the shear 
bond strength of orthodontic adhesive systems to permanent enamel, whether used with acid etching or laser etching without any significant difference between the two methodologies. The authors explained that the presence of 10-MDP copolymer in universal adhesives has been documented to be capable of bonding to enamel and dentin effectively, forming a nano-layer at the adhesive interface. It is composed of calcium salt of MDP with low solubility that yields beneficial effect in terms of bond strength. Universal adhesive was also used for bonding of samples in the current research, which might have improved the quality of bonding to the etched enamel samples in all the study groups.

On the other hand, other researchers (40-42) emphasized that adhesion to laser ablated or laser etched dentin and enamel of permanent teeth is lower compared to conventional rotary preparation and acid etching. They resorted their conclusions to variations in energy outputs, presence of substructural damage as fissuring of enamel and extensive cracking caused by laser beam outputs that lead to insufficient resin penetration, and they pointed out for the need for standards for laser energy output in relation to the different tooth substrates.

The effects of laser pretreatment prior to bonding to primary teeth cannot be extrapolated from those applied to permanent tooth substrates, owing to the unique nature of primary enamel. Notwithstanding, the scarce literature still report inconclusive outcomes from laser pretreatment procedures. Some studies on shear bond strength to the enamel of primary teeth reported superior results in the Er:YAG laser group compared with acid-etching control, or similar results to the control group mechanically prepared and acid-etched ${ }^{(43,44)}$. Another study described better composite resin marginal adaptation was obtained when Er:YAG laser preparation was followed by total acid etching ${ }^{(45)}$, which accords our result that the highest
SBS mean was obtained in the combined laseretched /acid-etched study group.

Similarly, Bahrololoomi et al. ${ }^{(21)}$, stated that if laser is to be used for tooth preparation, it must be necessarily accompanied by acid etching. And that the maximum bond strength values relative to their study groups belonged to bur and acid-etching preparation in dentin and enamel followed by laser preparation and etching; and laser preparation followed by resin bonding without etching resulted in the lowest bond strength. They argued that lower bond strength values in the laser groups were probably due to the pulsing nature of laser, irregular pattern of etching, creating a surface without efficient undercuts in spite of increased surface roughness and subsequently interfering with adequate resin diffusion.

Due to difference in methodology, type of laser and laser parameters adopted in this study and the previously mentioned studies, comparing the obtained results could not be a valid alternative. However, it can be inferred that because of the diminished bond strength to primary enamel compared to permanent teeth imposed by its inherent morphological and physiological differences, an attempt could be made by combining the assets of acid and laser etching regarding primary enamel conditioning prior to resin bonding.

\section{CONCLUSIONS}

- Laser etching of primary enamel yielded comparable result to acid etching in terms of comparable shear bond strength.

- The shear bond strength of resin composite to primary enamel can be improved by laseretching followed by acid- etching

\section{REFERENCES}

1. Kubo S, Kawasaki A, Hayashi Y. Factors associated with the longevity of resin composite restorations. Dent Mater J. 2011;30:374-383. doi: 10.4012/dmj.2010-191. 
2. Bohaty B, Spencer P, Misra, Ye, Sene. Posterior composite restoration update: focus on factors influencing form and function. Clin Cosmet Investig Dent. 2013;5:33-42. doi: $10.2147 /$ CCIDE.S42044

3. Hingan P, Sandhu M. Shear Bond Strength of Self-etching Adhesives to Cavities Prepared by Diamond Bur or Er , Cr : YSGG Laser and Effect of Prior Acid Etching. J Adhes Dent. 2015;17(6):505-512. doi:10.3290/j.jad.a35259

4. De Oliveira MT, Arrais CAG, Aranha AC, et al. Micromorphology of resin-dentin interfaces using one-bottle etch\&rinse and self-etching adhesive systems on lasertreated dentin surfaces: A confocal laser scanning microscope analysis. Lasers Surg Med. 2010;42(7):662-670. doi:10.1002/lsm.20945

5. 5. sWilson PR, Beynon AD. Mineralization differences between human deciduous and permanent enamel measured by quantitative microradiography. Arch Oral Biol. 1989;34(2):85-8. doi:10.1016/0003-9969(89)90130-1

6. 6. Arends J, Jongebloed WL. Dislocations and dissolution in apatites: Theoretical considerations. Caries Res. 1977;11(3):186-8.doi:10.1159/000260266

7. Sabel N. Enamel of primary teeth--morphological and chemical aspects. Swed Dent J Suppl. 2012;5(222):1$77,2 \mathrm{p}$ preceding i. http://www.ncbi.nlm.nih.gov/ pubmed/22515039.

8. Rythén M, Norén JG, Sabel N, et al. Morphological aspects of dental hard tissues in primary teeth from preterm infants. Int J Paediatr Dent. 2008;18(6):397-406

9. Lopes D, Mota C, Pereira D, Zezell DM, Gomes ASL. A Comparative Study Between Acid-etching and Er,Cr:YSGG Laser Irradiation on Enamel Surface Evaluated by OCT and SEM. In: Biophotonics Congress: Biomedical Optics Congress 2018 (Microscopy/Translational/ Brain/OTS). Washington, D.C.: OSA; 2018:JTh3A.15. doi:10.1364/TRANSLATIONAL.2018.JTh3A.15

10. Pires PT, Ferreira JC, Oliveira SA, Azevedo AF, Dias WR, Melo PR, et al. Shear bond strength and SEM morphology evaluation of different dental adhesives to enamel prepared with Er:YAG laser. Contemp Clin Dent 2013;4:20-6.

11. Keller U, Hibst R, Geurtsen W, Schilke R, Heidemann D, Klaiber B, et al. Erbium:YAG laser application in caries therapy. Evaluation of patient perception and acceptance. J Dent 1998;26:649-56.

12. Chimello-Sousa DT, de Souza AE, Chinelatti MA, Pécora JD, Palma-Dibb RG, Milori Corona SA, et al. Influence of Er:YAG laser irradiation distance on the bond strength of a restorative system to enamel. J Dent 2006;34:245-51.

13. Moshonov J, Stabholz A, Zyskind D, Sharlin E, Peretz B. Acid-etched and erbium:Yttrium aluminium garnet laser treated enamel for fissure sealants: A comparison of microleakage. Int J Paediatr Dent 2005;15:205-9

14. Fowler BO, Kuroda S. Changes in heated and in laser-irradiated human tooth enamel and their probable effects on solubility. Calcif Tissue Int 1986;38:197-208.

15. Cehreli SB, Gungor HC, Karabulut E. Er, Cr:YSGG laser pretreatment of primary teeth for bonded fissure sealant application: A quantitative microleakage study. J Adhes Dent 2006;8:381-6.

16. AlHumaid J,Alagl AS, Bedi S. Effect of erbium laser on microtensile bond strength of fissure sealant in primary teeth: an in vitro study. Saudi J Med Med Sci. 2018;6(1):27-31. doi: 10.4103/sjmms.sjmms_102_17.

17. Ergücü Z, Celik EU, Unlü N, Türkün M, Ozer F. Effect of Er, Cr:YSGG laser on the microtensile bond strength of two different adhesives to the sound and caries-affected dentin. Oper Dent 2009;34:460-6.

18. Sungurtekin E, Oztaş N. The effect of erbium, chromium: yttrium-scandium-gallium-garnet laser etching on marginal integrity of a resin-based fissure sealant in primary teeth. Lasers Med Sci 2010;25:841-7.

19. Cardoso MV, De Munck J, Coutinho E, Ermis RB, Van Landuyt K, de Carvalho RC, et al. Influence of Er, Cr:YSGG laser treatment on microtensile bond strength of adhesives to enamel. Oper Dent 2008;33:448-55.

20. Alkhudhairy F, Naseem M, Bin-Shuwaish M, Vohra F. Efficacy of Er Cr: YSGG laser therapy at different frequency and power levels on bond integrity of composite to bleached enamel. Photodiagnosis Photodyn Ther. 2018;22(February):34-38. doi:10.1016/j.pdpdt.2018.02.019

21. Shafiei F, Sardarian A, Fekrazad R, Farjood A. Comparison of shear bond strength of orthodontic brackets bonded with a universal adhesive using different etching methods. Dental Press J Orthod. 2019 Sep 5;24(4):33.e1-33.e8. doi: 10.1590/2177-6709.24.4.33.e1-8.onl. PMID: 31508704; PMCID: PMC6733226.

22. Luong E, Shayegan A. Assessment of microleakage of class $\mathrm{V}$ restored by resin composite and resin-modified glass ionomer and pit and fissure resin-based sealants following Er:YAG laser conditioning and acid etching: in vitro study. Clin Cosmet Investig Dent. 2018 May 30;10:8392. doi: 10.2147/CCIDE.S153989. PMID: 29881311; PMCID: PMC5985794. 
23. Sagir S, Usumez A, Ademci E, Usumez S. Effect of enamel laser irradiation at different pulse settings on shear bond strength of orthodontic brackets. Angle Orthod. 2013;83(6):973-80.

24. Basaran G, Hamamci N, Akkurt A. Shear bond strength of bonding to enamel with different laser irradiation distances. Lasers Med Sci.2011;26(2):149-56.

25. Kim JH, Kwon OW, Kim HI, Kwon YH. Effectiveness of an Er:YAG laser in etching the enamel surface for orthodontic bracket retention. Dent Mater J. 2005;24(4):596-602.

26. Lasmar MF, Reher VG, Lalloo R, Reher P. Enamel demineralization and bracket bond strength when etching with acid and /or Er:YAG laser.Aust Dent J. 2012;57(2):190-5.

27. Bahrololoomi Z, Kabudan M, Gholami L. Effect of Er:YAG Laser on Shear Bond Strength of Composite to Enamel and Dentin of Primary Teeth. J Dent (Tehran). 2015;12(3):163170.http://www.ncbi.nlm.nih.gov/pubmed/26622267.

28. Ayar MK, Erdemir F. Bonding performance of universal adhesives to er,cr:YSGG laser-irradiated enamel. Microsc Res Tech. 2017;80(4):387-393. doi:10.1002/jemt.22807

29. Hoshing U, Patil S, Medha A, Bandekar S. Comparison of shear bond strength of composite resin to enamel surface with laser etching versus acid etching: An in vitro evaluation. J Conserv Dent. 2014;17(4):320.doi:10.4103/09720707.136438

30. Alkhudhairy F, Naseem M, Bin-Shuwaish M, Vohra F. Efficacy of Er Cr: YSGG laser therapy at different frequency and power levels on bond integrity of composite to bleached enamel. Photodiagnosis Photodyn Ther. 2018;22(February):34-38. doi:10.1016/j.pdpdt.2018.02.019

31. Vohra F, Alghamdi A, Aldakkan M, et al. Influence of Er: Cr: YSGG laser on adhesive strength and microleakage of dentin bonded to resin composite. In-vitro study. Photodiagnosis Photodyn Ther. 2018;23:342346. doi:10.1016/j. pdpdt.2018.08.002

32. Jhingan P, Sandhu M. Shear Bond Strength of Self-etching Adhesives to Cavities Prepared by Diamond Bur or Er , Cr : YSGG Laser and Effect of Prior Acid Etching. 2015;17(6):505-512. doi:10.3290/j.jad.a35259

33. Rehman F, Kumar G, Goswami M, Dhillon JK. Comparison of shear bond strength of reattached incisor fragment using Er,Cr:YSGG laser etching and conventional acid etching: An in vitro study. Laser Ther. 2016 Jun 29;25(2):115-120. doi: 10.5978/islsm.16-OR-09. PMID: 27721563; PMCID: PMC4961669.

34. Jacboson B, Berger J, Kravitz R, Patel P. Laser pediatric crowns performed without anesthesia: A contemporary technique. J Clin Pediatr Dent 2003;28:11-2.

35. Wigdor HA, Walsh JT Jr., Featherstone JD, Visuri SR,
Fried D, Waldvogel JL, et al. Lasers in dentistry. Lasers Surg Med 1995;16:103-33.

36. Liu Y, Hsu CY, Teo CM, Teoh SH. Subablative Er:YAG laser effect on enamel demineralization. Caries Res 2013;47:63-8.

37. Martinez-Insua A, Da Silva Dominguez L, Rivera FG, Santana-Penin UA. Differences in bonding to acid-etched or Er:YAG-laser-treated enamel and dentin surfaces. J Prosthet Dent. 2000. September;84(3):280-8.

38. Dilip S, Srinivas S, Mohammed Noufal MN, Ravi K, Krishnaraj R, Charles A. Comparison of surface roughness of enamel and shear bond strength, between conventional acid etching and erbium, chromium-doped: Yttrium scandiumgallium-garnet laser etching - An in vitro study. Dent Res J (Isfahan). 2018 Jul-Aug;15(4):248-255. PMID: 30123301; PMCID: PMC6073948.

39. Basaran G, Ozer T, Berk N, Hamamci O. Etching enamel for orthodontics with an erbium, chromium: yttriumscandium-gallium-garnet laser system. Angle Orthod. 2007;77:117-23.

40. Hossain, M., Y. Nakamura, Y. Tamaki, Y. Yamada, Y. Murakami, and K. Matsumoto. Anatomic analysis and knoop hardness measurement of the cavity flor prepared by Er,Cr:YSGG laser irradiation in vitro. J Oral Rehabil 2003. 30:515-21.

41. Lee BS, Hsieh TT, Lee YL, Lan WH, Hsu YJ, Wen PH, et al. Bond strengths of orthodontic bracket after acid-etched, Er: YAG laser-irradiated and combined treatment on enamel surface. Angle Orthod. 2003. October;73(5):565-70

42. Dunn W.J, Davis JT, Bush AC. Shear bond strength and SEM evaluation of composite bonded to Er:YAG laser prepared dentin and enamel. Dent Mater 2005;21(7): 616-624.

43. Lessa FC, Mantovani CP, Barroso JM, Chinelatti MA, Palma- Dibb RG, Pécora JD, Borsatto MC. Shear bond strength to primary enamel: influence of Er:YAG laser irradiation distance. J Dent Child (Chic).2007 Jan-Apr;74(1):26-9.

44. Wanderley RL, Monghini EM, Pecora JD, Palma-Dibb RG, Borsatto MC. Shear bond strength to enamel of primary teeth irradiated with varying Er:YAG laser energies and SEM examination of the surface morphology: an in vitro study. Photomed Laser Surg 2005 Jun;23(3):260-7.

45. Bertrand MF, Semez G, Leforestier E, Muller-Bolla M, Nammour S, Rocca JP. Er:YAG laser cavity preparation and composite resin bonding with a single-component adhesive system: relationship between shear bond strength and microleakage. Lasers Surg Med 2006 Jul;38(6):615-23. 